\title{
Methodology for mobile measurements of carbon dioxide within the urban canopy layer
}

\author{
Sascha Henninger ${ }^{1, *}$, Wilhelm Kuttler ${ }^{2}$ \\ ${ }^{1}$ Institute of Natural Sciences, Dept. of Geography, Universitätsstr. 1, University Koblenz-Landau, Campus Koblenz, \\ 56070 Koblenz, Germany \\ ${ }^{2}$ Institute of Geography, Dept. of Applied Climatology and Landscape Ecology, Universitätsstr. 5, University Duisburg-Essen, \\ Campus Essen, 45141 Essen, Germany
}

\begin{abstract}
We tested a method for high-resolution measurement of $\mathrm{CO}_{2}$ within the urban canopy layer for urban land-use types in Essen, Germany $\left(51^{\circ} 28^{\prime} \mathrm{N}, 7^{\circ} 0^{\prime} \mathrm{E}\right.$; population: 582 000; area: $210 \mathrm{~km}^{2}$ ) between 2002 and 2005. $\mathrm{CO}_{2}$ was measured during calm weather on 50 mobile trips, and analysis of this data showed that the urban $\mathrm{CO}_{2}$ mixing ratio can be represented both temporally and spatially. Mobile measurement allows basic recurring $\mathrm{CO}_{2}$ patterns to be recorded, since close similarities can be observed in $\mathrm{CO}_{2}$ patterns within the urban canopy layer at different times if weather conditions are similar or the measurements are taken at the same time of the day. This method of measurement also allows the researcher to make fewer measuring trips than was initially planned. Statistical analysis confirmed that 4 measuring trips per season ( 2 for daytime and 2 for night time) are sufficient to obtain a representative and reliable picture of $\mathrm{CO}_{2}$ within the urban canopy layer.
\end{abstract}

KEY WORDS: Urban $\mathrm{CO}_{2} \cdot$ Urban environment $\cdot$ Mobile measurements · Air pollutants · Statistical analysis · Essen

Resale or republication not permitted without written consent of the publisher

\section{INTRODUCTION}

Important sources of atmospheric trace substances within urban environments include traffic, domestic fuel combustion, industrial facilities, and power stations. In the case of $\mathrm{CO}_{2}$ sources, vegetation must also be included (but on balance, more as a natural sink of anthropogenic $\mathrm{CO}_{2}$ ) (Nowak \& Crane 2001, Henninger 2005a, 2006a, Yang et al. 2005), as must human respiration (Lichtfouse et al. 2003, Henninger 2006b).

The global concentration of atmospheric $\mathrm{CO}_{2}$ has increased from about $280 \mathrm{ppm}$ (Leuenberger et al. 1992) - the pre-Industrial Revolution level-to over 379 ppm today (Laurimore 2007). It is likely that a similar increase in $\mathrm{CO}_{2}$ concentration has occurred at more local scales due the urbanization process. There is an increasing body of literature concerning $\mathrm{CO}_{2}$ within urban environments; the main focus of these investigations is on turbulent vertical flux measurements of carbon dioxide (e.g. Reid \& Steyn 1997, Nemitz et al. 2002, Grimmond et al. 2004, Moriwaki \&
Kanda 2004, Salmond et al. 2005, Velasco et al. 2005, Vogt et al. 2005; vertical turbulent fluxes are representative of concentration and fluxes, which are horizontally homogeneous) and the analysis of stable carbon isotopes to determine $\mathrm{CO}_{2}$ sources (e.g. Clarke-Thorne \& Yapp 2003, Pataki et al. 2003, Carmi et al. 2005). $\mathrm{CO}_{2}$ measurement in these studies was mostly from urban measuring stations; these studies tend to be time-, labour- and equipment-intensive, since it is important to ensure that measurements are representative of the stations' surroundings. Few publications have dealt with the methodology of mobile measurements of $\mathrm{CO}_{2}$ within urban environments, especially within the urban canopy layer in relation to urban land use (Henninger 2005b, Kuttler \& Weber 2006).

Previous research using mobile measurements followed a definite measuring route in order to determine typical heterogeneous fields of air pollutants within urban spaces (e.g. Luria et al. 1990, Idso et al. 1998, Shorter et al. 1998, Kuttler \& Strassburger 1999, Idso et al. 2001, Bukowiecki et al. 2002, Henninger \& Kuttler 
2004, Henninger 2005a, 2006a,b). Since these investigations were only made over a short period (from a few days to several weeks), it was impossible to get representative and reliable data on the atmospheric $\mathrm{CO}_{2}$ concentration within the urban canopy layer across different seasons and different times of the day (across which there can be substantial variation in urban $\mathrm{CO}_{2}$ ). Moreover, there does not yet exist a standardized method for measuring trace gases-especially $\mathrm{CO}_{2}$-with a mobile laboratory. For this reason it is nearly impossible to compare the results of the different investigations with regard to travelling time and speed, length of measuring route, frequency of measurement, time of day, and trace gases recorded, because each investigation uses a different measuring method and focuses on a different aspect (e.g. $\mathrm{CO}_{2}$ in relation to land use, or in relation to time of day).

The aim of this investigation was to present a method for determing $\mathrm{CO}_{2}$ concentration within the urban canopy layer through mobile measurements. This method allows for both reproducibility and statistical verifiability of the final results.

\section{MOBILE MEASUREMENTS}

An advantage of using a mobile laboratory to make air quality measurements is the high level of temporal and spatial representation that would be difficult to achieve with standardized stationary measurements. Continuous measurements mean that a large number of measurements are made over a short time, and within a small area; the measuring frequency of the analyzers is easily increased to high levels by assigning numerous additional measuring points along the measuring route. In addition, mobile measuring provides a solution to studies with a short time frame (and thus only small amounts of data), since a large number of measuring trips can be made over this short period, enabling a larger amount of data to be gathered than would be possible for fixed stations. Continuous mobile measurements along a measuring route also allow the data gap between fixed stations to be closed (Henninger 2005a, 2006a,b). To achieve the same result through non-mobile measurements would be enormously complex.

\subsection{Measuring method}

Measuring trips were made during day and night using the mobile laboratory of the Deptartment of Applied Climatology and Landscape Ecology, University Duisburg-Essen. $\mathrm{CO}_{2}$ was measured by infrared radiation absorption at the height of $1.50 \mathrm{~m}$ a.g.l. (above ground level) on the right-hand side of the mobile laboratory, to minimise the effect of exhaust from passing vehicles on the measurements. Meteorological values were also recorded. The mobile laboratory travelled at a maximum speed of $8 \mathrm{~m} \mathrm{~s}^{-1}$. Analysers measured at a frequency of $1 \mathrm{~Hz}$. Using the delay time of the analyzers (e.g. $\mathrm{CO}_{2}=13 \mathrm{~s}$ ) and logged GPS coordinates, it was possible to relate one recorded value to its measuring point along the measuring route.

The exhaust of vehicles driving very slowly or stopping in front of the mobile laboratory because of red traffic lights or road work might influence the trace gas concentration, which would give false results. Therefore, attention was paid to a theoretical horizontal safety distance $(\geq 2 \mathrm{~m})$ of cars driving in front of the mobile laboratory based on Clifford et al. (1997). Minimizing these influences along the measuring route meant manually noting the traffic slow-downs and the obvious presence of cars within the safety distance using a remote control device which marked these events within the database. Thus, it was possible to omit the interruptions manually in the data processing, which allowed for an almost continuous record of the $\mathrm{CO}_{2}$ pattern along the measuring route. Although there were no significant differences $(p>0.5)$ between corrected and uncorrected results for all measuring trips between winter 2002 and summer $2005\left(R^{2}=0.88\right.$; $\mathrm{n}=50)$, the correlation coefficients $\left(\mathrm{R}^{2}=0.97 ; \mathrm{p}>0.5\right)$ of nighttime measurements $(\mathrm{n}=25)$; were significantly higher than during the daytime measurements $\left(\mathrm{R}^{2}=\right.$ $0.79 ; \mathrm{p}>0.5 ; \mathrm{n}=25$; Fig. 1) because of the lower probability of traffic-induced interruptions and more stable atmospheric conditions than during the night. The stability index can be calculated using the data from the 4 meteorological stations installed along the measuring route (Pasquill 1961, Polster 1969) (see Fig. 2).

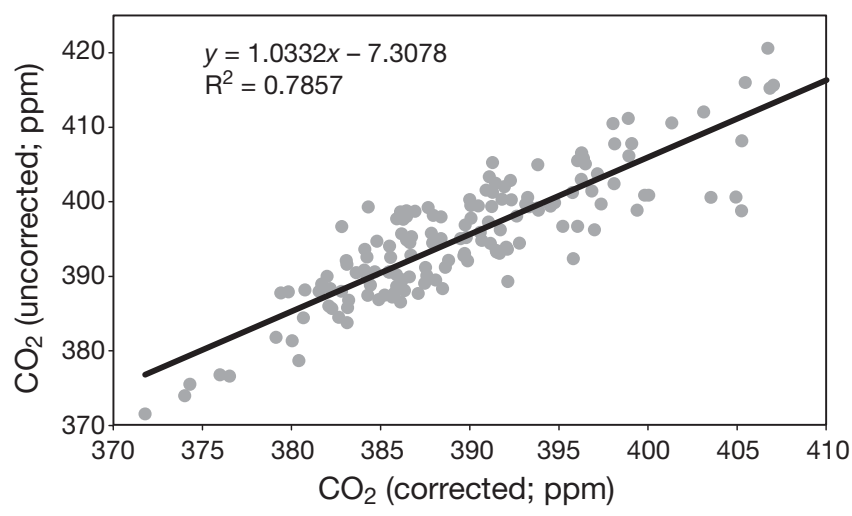

Fig. 1. Comparison of corrected and uncorrected $\mathrm{CO}_{2}$ on all daytime measuring trips $(\mathrm{n}=25)$ of the measuring period 2002-2003 along the measuring route within the urban area of Essen, Germany 


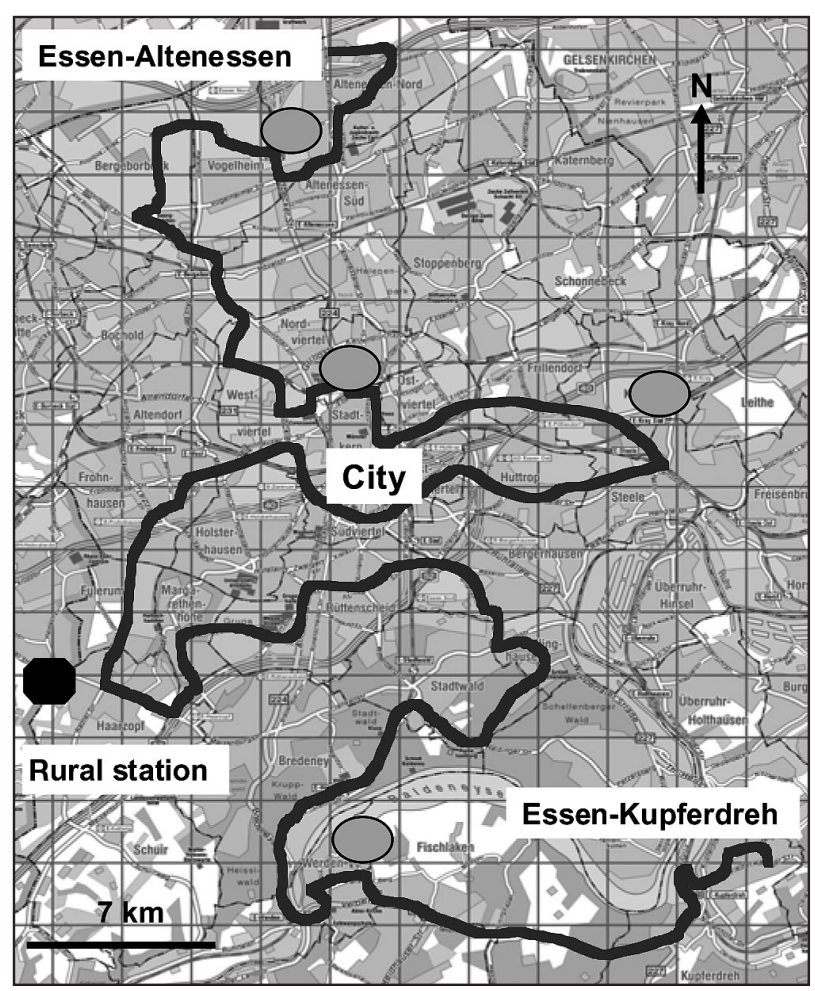

Fig. 2. Street map of Essen, Germany, showing location of $\mathrm{CO}_{2}$ measuring route (thick line), $\mathrm{CO}_{2}$ rural background station (O) and meteorological stations (O). Essen-Kupferdreh and Essen-Altenessen: beginning and end, respectively, of the measuring route

Nevertheless, interruptions were filtered out, even though it provided higher correlations and no significant differences between corrected and uncorrected data.

In view of spatial fluctuations of trace gas concentration, caused, for example, by the change of land use or the structure of housing along the measuring route, average values of so-called homogeneous road sections were calculated (Kuttler \& Wacker 2001, Henninger \& Kuttler 2004). With a length of 63 kilometers, the measuring route could be subdivided into 61 road sections with a length of slightly more than $1 \mathrm{~km}$ each. Each of these route sections had more or less homogenous land-use types; however, the length of a section could vary from one measuring trip to another, because a changes in land use were not always homogeneous. Sub-division into road sections enabled direct comparisons of single measuring trips, aiding the interpretation of data. In addition, salient measurements could, at any point, be manually marked within the dataset while driving. Between each road section, $\sim 40 \mathrm{~m}$ (i.e. $5 \mathrm{~s}$ of travel) between neighbouring sections were discounted to reduce the influence of one road section on another (Henninger 2005a, 2006a).

\subsection{Measured area}

Due to its location within the centre of the Ruhrgebiet conurbation, the city of Essen, Germany $\left(51^{\circ} 28^{\prime} \mathrm{N}, 7^{\circ} 0^{\prime} \mathrm{E}\right.$; population: 582000 ; area: $210 \mathrm{~km}^{2}$ ), should be representative of the Rhine-Ruhr region. Concerning its structure of $\mathrm{CO}_{2}$ emission (energy production 39\%, transport sector $21 \%$, industrial sector $19 \%$, private sector $15 \%$, others $4 \%$ ) within the urban canopy layer of Essen, exhaust gases of traffic and domestic fuel (with low emission heights - e.g. chimneys of houses are not very high, compared to industrial chimneys) are the most important determined influencing factors within the area of investigation due to the measuring height of air quality indicators.

A total of 50 mobile measuring trips were made in Essen between winter 2002 and summer 2005 during day and night, on weekdays and several weekends. The measured route started in the southern part of the city (Essen-Kupferdreh, Road Section 1) and ended after $63 \mathrm{~km}$ to the north of Essen (Essen-Altenessen, Road Section 61); this route represented all major types of urban land use (Fig. 2). Also represented was the rural $\mathrm{CO}_{2}$ station in an agricultural field in southwest Essen, maintained by the Deptartment of Applied Climatology and Landscape Ecology (Fig. 2). This background station was used for comparison of $\mathrm{CO}_{2}$ and meteorological values collected throughout the mobile measurements (see Table 1).

\subsection{Measuring times}

The mobile measurements were mostly taken during clear and calm weather conditions (wind speed $v \leq$ $1.5 \mathrm{~m} \mathrm{~s}^{-1}$ ) at different times of the day and year in order to observe the influence of seasonal vegetation or the contribution of domestic fuel emissions on the $\mathrm{CO}_{2}$ concentration within the urban canopy layer. Low wind speeds allowed a view of the urban $\mathrm{CO}_{2}$, because of the low levels of exchange within the different route

Table 1. Average $\mathrm{CO}_{2}$ concentration $\pm \mathrm{SD}$ (standard deviation) for the mobile measuring trips and the rural station in 20022003, and also for different seasons (December 2002-November 2003). Difference: percent difference between urban and rural sites, $\left([\bar{X}\right.$ bar $] \sigma_{\text {urban }}-[\bar{X}$ bar $\left.] \sigma_{\text {rural }}\right) /[\bar{X}$ bar $] \sigma_{\text {rural }} \times 100 \%$

\begin{tabular}{|lccc|}
\hline Period & \multicolumn{2}{c|}{$\mathrm{CO}_{2}(\mathrm{ppm})$} & Difference \\
& {$[\bar{x}$ bar $] \sigma_{\text {urban }}$} & {$[\bar{x}$ bar $] \sigma_{\text {rural }}$} & $(\%)$ \\
\hline Entire period & $408 \pm 20.66$ & $379 \pm 5.04$ & 7.7 \\
Winter 2002/2003 & $415 \pm 21.33$ & $373 \pm 4.16$ & 11.3 \\
Spring 2003 & $404 \pm 17.69$ & $382 \pm 5.05$ & 5.8 \\
Summer 2003 & $393 \pm 17.55$ & $369 \pm 8.09$ & 6.5 \\
Autumn 2003 & $420 \pm 26.09$ & $392 \pm 2.84$ & 7.1 \\
\hline
\end{tabular}




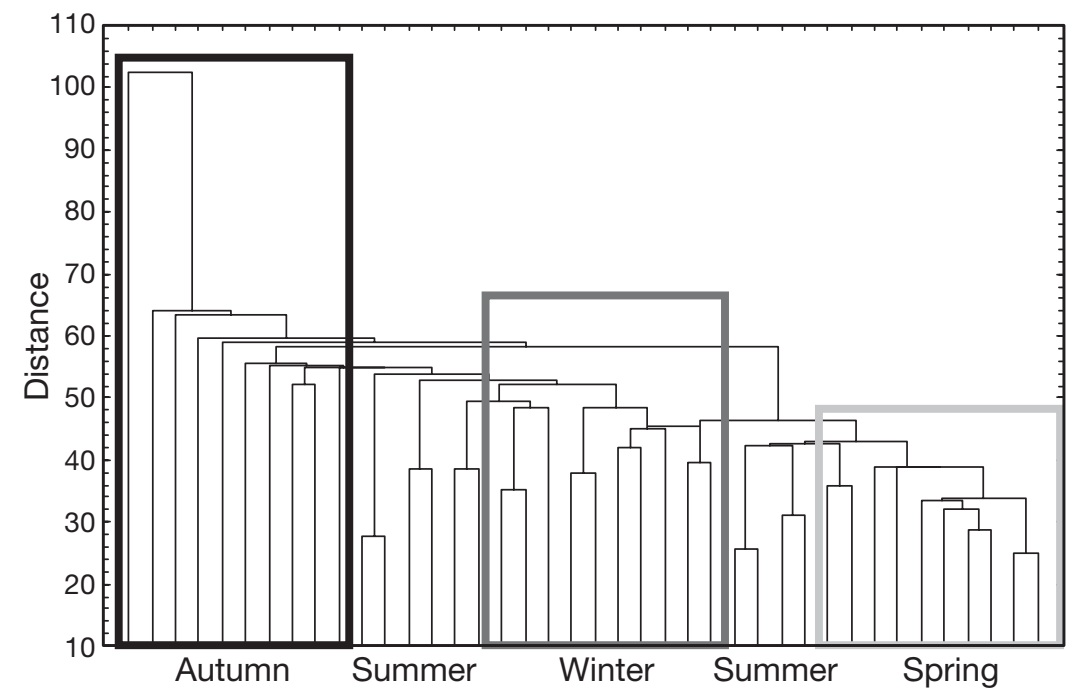

Fig. 3. Cluster diagram (single linkage Euclidean distances) of $\mathrm{CO}_{2}$ measurements $(\mathrm{n}=40)$ within the urban area of Essen, Germany, for the measuring period December 2002 to November 2003 (black square: autumn cluster; mid-grey square: winter cluster; light-grey square: spring cluster)

of the fall, winter, and spring measuring trips-are found (Fig. 3). It can be assumed that the measuring trips for one season $(n=10)$ will have relatively little variance. Summer is subdivided into 2 clusters (Fig. 3). This can be explained by high concentration differences between day- and nighttime measurements (mainly due to photosynthesis/ $\mathrm{CO}_{2}$ respiration and atmospheric conditions) and thus completely different $\mathrm{CO}_{2}$ patterns along the measuring route. Therefore, daytime and nighttime differences could be disregarded. In fact, the other 3 seasons had recognizable (but lower) concentration differences between day- and nighttime measuring trips.

A significance test demonstrated a statistically significant difference between the seasons. Analysis of the seasonal differences revealed that the measuring

sections along the measuring route. Due to the fact that rush-hour only gives a snapshot of the daily air pollution of a city, measurements were taken before (04:0007:00 and 13:00-16:00 h) and after (10:00-13:00 and 19:00-22:00 h) daily traffic peaks in order to measure the air it had a homogeneous mix of constituents along the measuring route, and to obtain representative measures of $\mathrm{CO}_{2}$ within the urban canopy layer. Measuring trips were also made between 23:00 and 02:00 $\mathrm{h}$, to cover the transition in $\mathrm{CO}_{2}$ levels that takes place overnight.

With assistance of these different measuring times, it was possible to show the natural diurnal variations in $\mathrm{CO}_{2}$ concentration, influenced by the gas-exchange cycle of the biosphere (photosynthesis and respiration of plants, soil exchange). Likewise, it was possible to observe the atmospheric boundary layer conditions in relation to the times of the day and its influence on urban $\mathrm{CO}_{2}$ (Henninger 2006a).

\section{RESULTS}

Statistical evaluation of the data using significance testing, correlation analysis, and product-moment analysis (Schönwiese 2000) should determine whether a statistically significant representation of the trace gas concentration is obtainable, and if the methodology using mobile measurements is valid and reliable.

A single linkage cluster analysis should indicate if it is possible to subdivide the $\mathrm{CO}_{2}$ data from all measuring trips during winter 2002 and fall 2003 (n = 40) into meaningful groups. Three separate groups — composed trips could be divided into 'seasonal clusters' (see Fig. 3).

Fig. 4 shows the measurements taken during the summer of 2003 (June to August; $\mathrm{n}=10$ ). It indicates 5 clusters that are identical with the 5 times that measures were taken. The diagram also shows the division of the summer season (see above paragraph). Measuring trips during the day $(10: 00-13: 00 ; 13: 00-16: 00 \mathrm{~h})$ and night (23:00-02:00; 04:00-07:00 h) create a generic cluster (Fig. 4). The measuring time from 19:00-22:00 $\mathrm{h}$ was assigned to daytime measuring trips, because it was before sunset.

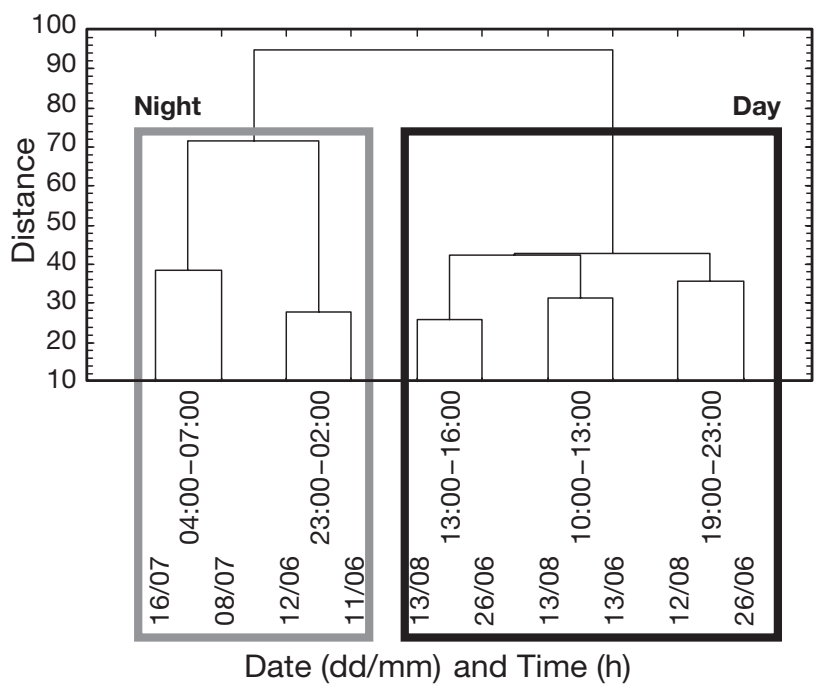

Fig. 4. Cluster diagram (single linkage Euclidean distances) of $\mathrm{CO}_{2}$ measuring trips during summer 2003 ( $\mathrm{n}=10$; see Fig. 3) within the urban area of Essen, Germany. Black square: nighttime measuring trips; grey square: daytime measuring trips 


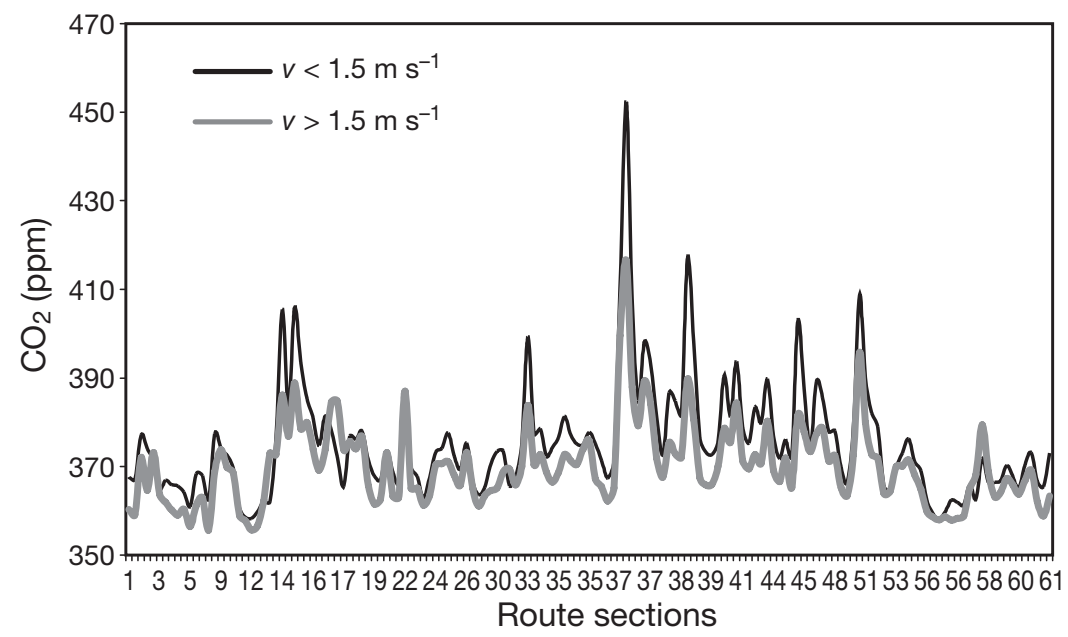

Fig. 5. $\mathrm{CO}_{2}$ patterns $\left(\mathrm{R}^{2}=0.91 ; \mathrm{p}>0.5\right)$ on 16 June (grey line) and 12 August (black line) 2003 (measuring time: 19:00-22:00 h). Although they are both part of one cluster (see Fig. 4) they were only affected by the wind speed (v) (summer 2003)

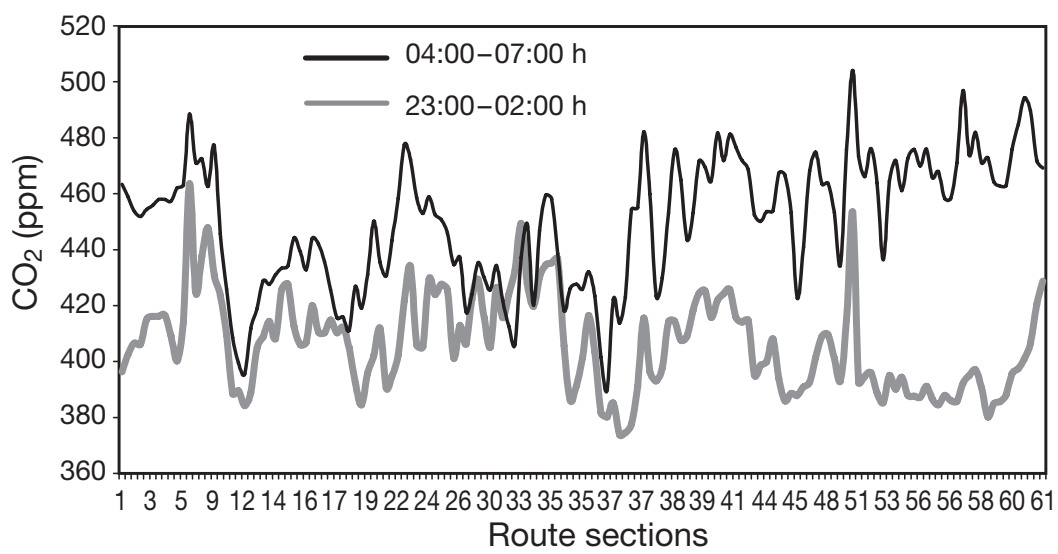

Fig. 6. $\mathrm{CO}_{2}$ patterns of measuring trips within the urban area of Essen, Germany $\left(\mathrm{R}^{2}=0.17 ; \mathrm{p}<0.01\right)$, for 11 June and 8 July 2003 , with different measuring times (23:00-02:00 and 04:00-07:00 h, respectively). These 2 measuring trips are part of 2 different clusters in Fig. 4, although they have a comparable wind speed $\left(v \leq 1.5 \mathrm{~m} \mathrm{~s}^{-1}\right)$
A cluster of measures were taken (see Fig. 4) at the same time of day (e.g. 16 June 2003 and 12 August 2003, 19:00-22:00 h), from which we tested the correlation between 2 features: route sections and average $\mathrm{CO}_{2}$ concentration of the homogeneous road sections (Fig. 5). The results indicate a uniform allocation of $\mathrm{CO}_{2}$ along the measuring route due to the high correlation coefficient $\left(\mathrm{R}^{2}=\right.$ 0.91). The difference between $\mathrm{CO}_{2}$ concentrations between the 2 curves in Fig. 5 could be explained by differing wind speeds (determined by 4 different urban meteorological stations; see Fig. 2) during the measuring trips (16 June 2003: $v>1.5 \mathrm{~m} \mathrm{~s}^{-1}$ and 12 August 2003: $v \leq$ $1.5 \mathrm{~m} \mathrm{~s}^{-1}$ ). Obviously, wind speed was the main influence on the mixing ratio but not the spatial $\mathrm{CO}_{2}$ pattern along the measuring route. In fact, long-range transport of $\mathrm{CO}_{2}$ can be neglected here, because higher $\mathrm{CO}_{2}$ concentrations were detected during $V \leq 1.5 \mathrm{~m} \mathrm{~s}^{-1}$. Hence, stable and calm atmospheric conditions might have caused an accumulation of the trace gas.

A comparison of 2 measuring trips not connected in one cluster (e.g. 11 June 2003: 23:00-02:00 $\mathrm{h}$ and 8 July 2003: 04:00-07:00 h) support the results mentioned above and indicated in Figs. 4 \& 5 , demonstrating that the 2 measuring trips are unique from each other (Fig. $6 ; \mathrm{R}^{2}=$ 0.17). This could be partly explained by differing atmospheric conditions, but the main factor was variation in traffic density related to different measuring times.

Table 2. Product-moment-correlation coefficients for $\mathrm{CO}_{2}$ patterns of measuring trips $(\mathrm{n}=10)$ in Essen, Germany, in winter 2002/2003 (evening: 19:00-22:00 h; midnight: 23:00-02:00 h; morning: 10:00-13:00 h; day: 13:00-16:00 h; night: 04:00-07:00 h). Evening 1: 11.12.2002, Evening 2: 05.02.2003; Midnight 1: 06.01.2003, Midnight 2: 19.02.2003; Morning 1: 02.12.2002, Morning 2: 12.02.2003; Night 1: 19.12.2002, Night $2=12.02 .2003$; Day 1: 05.02.2003, Day 2: 18.02.2002

\begin{tabular}{|lcccccrrrrr|}
\hline & Evening 1 & Evening 2 & Midnight 1 & Midnight 2 & Morning 1 & Morning 2 & Night 1 & Night 2 & Day 1 & Day 2 \\
\hline Evening 1 & & 0.89 & 0.26 & 0.38 & 0.06 & 0.31 & -0.27 & -0.44 & 0.12 & -0.10 \\
Evening 2 & 0.89 & & 0.28 & 0.39 & 0.11 & 0.35 & -0.25 & -0.38 & 0.13 & -0.05 \\
Midnight 1 & 0.26 & 0.28 & & 0.85 & -0.12 & -0.09 & -0.21 & -0.20 & 0.22 & -0.02 \\
Midnight 2 & 0.38 & 0.39 & 0.85 & & -0.09 & -0.01 & -0.34 & -0.39 & 0.06 & -0.16 \\
Morning 1 & 0.06 & 0.11 & -0.12 & -0.09 & & 0.76 & 0.07 & 0.06 & 0.02 & 0.08 \\
Morning 2 & 0.31 & 0.35 & -0.09 & -0.01 & 0.76 & & 0.12 & 0.01 & 0.27 & 0.36 \\
Night 1 & -0.27 & -0.25 & -0.21 & -0.34 & 0.07 & 0.12 & & 0.92 & 0.47 & 0.48 \\
Night 2 & -0.44 & -0.38 & -0.20 & -0.39 & 0.06 & 0.01 & 0.92 & & 0.42 & 0.47 \\
Day 1 & 0.12 & 0.13 & 0.22 & 0.06 & 0.02 & 0.27 & 0.47 & 0.42 & 0.47 & 0.80 \\
Day 2 & -0.10 & -0.05 & -0.02 & -0.16 & 0.08 & 0.36 & 0.48 & 0.47 & 0.80 \\
\hline
\end{tabular}




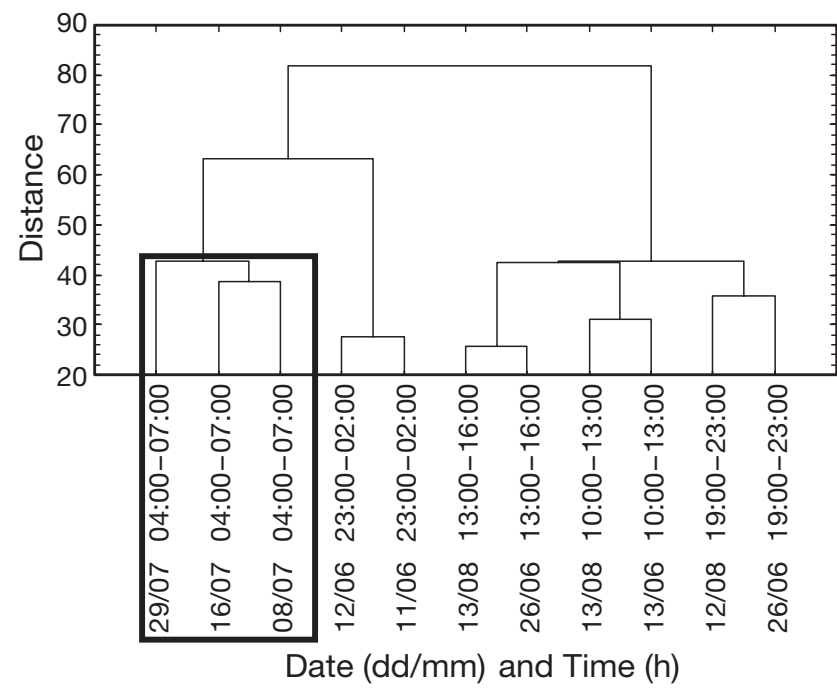

Fig. 7. Cluster diagram (single linkage euclidean distance) of measuring trips within the urban area of Essen, Germany, during summer $2003(\mathrm{n}=10)$ and an additional measuring trip in summer 2004 (29 July 2004; 04:00-07:00 h). Black square: measuring trips within one cluster with identical measuring times

The strength of the correlation be-tween the different measuring trips was determined using a productmoment correlation analysis, which revealed high correlations between measuring trips made at the same time of day, based on the average $\mathrm{CO}_{2}$ concentration of measuring trips in each season $(\mathrm{n}=40$; Table 2$)$. Different measuring times gave negative coefficients that were only slightly positive.

Furthermore, additional tests of significance show that the results are generalized across seasons; measuring trips made at the same time of the day displayed no significant differences $(p>0.5)$, whereas trips at different times did display a significance $(p<0.05)$, and even a high significance $(p<0.01)$. In sum, these results are significant for all seasons, and daytime as well as nighttime measuring trips. This demonstrates that there is a recurrent $\mathrm{CO}_{2}$ pattern along the measuring route, which is dependent upon the time of the day and season (Henninger \& Kuttler 2004, Henninger 2006a).

The recurrent $\mathrm{CO}_{2}$ pattern along the measuring route was confirmed during additional measuring trips (summer/winter 2004 and spring/summer 2005; same weather conditions). The trips were taken on the same measuring route (Fig. 2) and for the same 5 measuring times (see Section 2.3). Holding constant the time of day and the season, the $\mathrm{CO}_{2}$ pattern is quite similar across the measuring trips of 2002/2003, 2004, and 2005 $(\mathrm{r}>0.78 ; \mathrm{p}>0.5)$. For example, Figs. $7 \& 8$ offer an additional measuring trip within Essen during the summer of 2004. Analysis of the measuring trips during the summer of $2003(\mathrm{n}=10)$ and an additional one in the summer of 2004 gives a cluster for the period 04:00-07:00 h (Fig. 7). Fig. 8 displays the $\mathrm{CO}_{2}$ patterns of $3 \mathrm{~d}$ of measuring trips $\left(\mathrm{R}^{2}>0.78 ; \mathrm{p}>0.5\right)$, which are part of the black outlined cluster in Fig. 7 .

\section{DISCUSSION AND CONCLUDING REMARKS}

It is possible to show a highly frequented spatial as well as temporal solution of the $\mathrm{CO}_{2}$ mixing ratio within the urban canopy layer independent of the time of day and the season. In addition, there is a clear recurring $\mathrm{CO}_{2}$ pattern along the measuring route. However these results are generalizable only to the measuring route in calm weather conditions, and excluding periods of rush-hour traffic.

Our findings also indicate that the methodology and the tests of validity we used reliably tested $\mathrm{CO}_{2}$ patterns in the area investigated. Hence, the requirements for comparing 2 different measuring trips is that the time of the day and the season be the same.

Three facts can be postulated from these results; these have to be considered consecutively before planning measuring trips of $\mathrm{CO}_{2}$ within the urban canopy layer using a mobile laboratory.

(1) A comparison of different times of measuring revealed statistically significant differences $(p<0.05)$ between day- and nighttime measuring trips in clear and calm weather conditions, holding constant for rush hour traffic (Fig. 4). However, a comparison of night- and daytime measurements re-
Fig. 8. $\mathrm{CO}_{2}$ patterns of measuring trips within the urban area of Essen, Germany $\left(R^{2}>0.78 ; p>0.5\right)$, for 3 separate days with the same measuring time (04:00-07:00 h), which are part of one cluster (black square in Fig. 7), even though they were taken within different years (summer 2003 and summer 2004) 
vealed $p>0.1$. Hence, 2 measuring trips (one during the night, another during the day within the same weather conditions) seems to be sufficient to get a first idea of the $\mathrm{CO}_{2}$ pattern of an urban area dependent on the time of the day.

(2) In order to validate the results of the first 2 measuring trips, there should be 2 additional trips with identical day- and nighttime measuring times as well as very similar atmospheric conditions as the first 2 trips. From this point, it should be possible to ascertain the recurrent $\mathrm{CO}_{2}$ pattern along the measuring route. The measuring trips between 2002 and 2005 have shown that further (3rd and 4th) measuring trips, during comparable atmospheric conditions and measuring times, present similar results. Thus, more than 4 measuring trips ( 2 during the day and 2 during the night) is unnecessary.

Finally, the results from 2002 through 2005 indicate that there were significant differences between the seasons $(p<0.05$; Fig. 3). Thus, the 4 measuring trips (see Section 2.3) are necessary for all 4 seasons. This would require 16 measuring trips ( 8 day- and 8 nighttime trips) within a 1 yr measuring period.

\section{LITERATURE CITED}

Bukowiecki N, Dommen J, Prevot ASH, Richter R, Weingartner U, Baltensperger U (2002) A mobile pollutant measurement laboratory: measuring gas phase and aerosol ambient concentrations with high spatial and temporal resolution. Atmos Environ 36:5569-5579

Carmi I, Haklay R, Rozalis S, Kronfeld J (2005) The concentration and $\delta^{13} \mathrm{C}$ of $\mathrm{CO}_{2}$ in the urban atmosphere of Tel-Aviv. Geochrono 24:59-61

Clarke-Thorne ST, Yapp CJ (2003) Stable carbon isotope constraints on mixing and mass balance of $\mathrm{CO}_{2}$ in an urban atmosphere: Dallas metropolitan area, Texas, USA. Appl Geochem 18(1):75-95

Clifford MJ, Clarke R, Riffat SB (1997) Local aspects of vehicular pollution. Atmos Environ 31(2):271-276

Grimmond CSB, Salmond JA, Oke TR, Offerle B, Lemonsu A (2004) Flux and turbulence measurements at a densely builtup site in Marseille: heat, mass (water and carbon dioxide), and momentum. J Geophys Res 109: D 24101, doi: 10.1029/ 2004JD004936

Henninger S (2005a) Analyse der atmosphärischen $\mathrm{CO}_{2}$-Konzentrationen am Beispiel der Stadt Essen (Analyzing the atmospheric $\mathrm{CO}_{2}$ concentration within the city of Essen, Germany). Essener Ökologische Schriften 23. Westarp Wissenschaften, Hohenwarsleben (in German)

Henninger S (2005b) Urban $\mathrm{CO}_{2}$-determination of urban air quality indicators. Koblenz Geogr Kolloq 27:55-74

Henninger S (2006a) Temporal and spatial influencing of urban atmospheric carbon dioxide concentration. Proc 6th Int Conf Urban Clim. International Association for Urban Climate, Gothenburg, p 136-139

Henninger S (2006b) Micro scale climatological and air quality modifications during a fair-sized event. Proc 6th Int Conf Urban Clim. International Association for Urban Climate, Gothenburg, p 80-83

Henninger S, Kuttler W (2004) Mobile measurements of carbon dioxide within the urban canopy layer of Essen, Germany.

Editorial responsibility: Helmut Mayer,

Freiburg, Germany
In: Proc 5th Symp Urban Environ. American Meteorological Society, Vancouver

Idso CD, Idso SB, Balling RC (1998) The urban $\mathrm{CO}_{2}$ dome of Phoenix, Arizona. Phys Geogr 19(2):95-108

Idso CD, Idso SB, Balling RC (2001) An intensive 2-week study of an urban $\mathrm{CO}_{2}$ dome in Phoenix, Arizona, USA. Atmos Environ 35:995-1000

Kuttler W, Strassburger A (1999) Air quality measurements in urban green areas: a case study. Atmos Environ 33:4101-4108

Kuttler W, Wacker T (2001) Analyse der urbanen Luftqualität mittels mobiler Messungen (Analyzing the urban air quality by mobile measurements). Oesterr Beitr Meteorol Geophys 27(399):1-16 (in German)

Kuttler W, Weber S (2006) Applied urban climate research: the examples of Essen and Osnabrück. Geogr Rundsch 7/8: 42-49

Laurimore J (2007) Greenhouse gases. National Oceanic and Atmospheric Administration. Available at: www.noaa.gov

Leuenberger M, Siegenthaler U, Langway CC (1992) Carbon isotope composition of atmospheric $\mathrm{CO}_{2}$ during the last ice age from Antarctic ice core. Nature 357:488-490

Lichtfouse E, Lichtfouse M, Jaffrezic A (2003) $\delta 13 C$ values of grass as a novel indicator of pollution by fossil-fuel-derived greenhouse gas $\mathrm{CO}_{2}$ in urban areas. Environ Sci Technol 37(1):87-89

Luria M, Weisinger R, Peleg M (1990) CO and $\mathrm{NO}_{\mathrm{x}}$ levels at the center of city roads in Jerusalem. Atmos Environ 24B:93-99

Moriwaki R, Kanda M (2004) Seasonal and diurnal fluxes of radiation, heat, water vapor, and carbon dioxide over a suburban area. J Appl Meteorol 43:1700-1709

Nemitz E, Hargreaves KJ, McDonald A, Dorsey JR, Fowler D (2002) Micrometeorological measurements of the urban heat budget and $\mathrm{CO}_{2}$ emissions on a city scale. Environ Sci Technol 36(14):3139-3146

Nowak DJ, Crane DE (2001) Carbon storage and sequestration by urban trees in the USA. Environ Pollut 116:381-389

Pasquill F (1961) The estimation of the dispersion of windborne material. Meteorol Mag 90:33-49

Pataki DE, Bowling DR, Ehleringer JR (2003) Seasonal cycle of carbon dioxide and its isotopic composition in an urban atmosphere: anthropogenic and biogenic effects. J Geophys Res 108, doi:10.1029/2003JD003865

Polster G (1969) Erfahrungen mit Strahlungs-, Temperaturgradient- und Windmessungen als Bestimmungsgrößen der Diffusionskategorien. Meteorol Rundsch 22:170-175

Reid KH, Steyn DG (1997) Diurnal variations of boundary-layer carbon dioxide in a coastal city: observation and comparison with model results. Atmos Environ 31(8):3101-3114

Salmond JA, Grimmond CSB, Roberts S, Offerle B (2005) Venting of heat and carbon dioxide from urban canyons at night. J Appl Meteorol 44:1180-1194

Schönwiese CD (2000) Praktische Statistik für Meteorologen und Geowissenschaftler (Practical statistics for meteorologists and geoscientists), 3rd edn. Gebrüder Bornträger Verlag, Berlin (in German)

Shorter JH, McManus JB, Kolb CE, Allwine EJ and 7 others (1998) Recent measurements of urban metabolism and trace gas respiration. Proc 2nd Symp Urban Environ. American Meteorological Society, Albuquerque, p 49-52

Velasco E, Pressley S, Allwine E, Westbug H, Lamb B (2005) Measurements of $\mathrm{CO}_{2}$ fluxes from Mexico City urban landscape. Atmos Environ 39:7433-7446

Vogt R, Christen A, Rotach MW, Roth M, Satyanarayana ANV (2005) Temporal dynamics of $\mathrm{CO}_{2}$ fluxes and profiles over a central European city. Theor Appl Climatol 84(1-3):117-126

Yang J, McBride J, Zhou J, Sun Z (2005) The urban forest in Beijing and its role in air pollution reduction. Urban For Urban Green 3 (2):65-78

Submitted: August 5, 2005; Accepted: March 3, 2007

Proofs received from author(s): June 18, 2007 